\title{
Influenza $A$ and $B$ outbreaks differed in their associations with climate conditions in Shenzhen, China
}

\author{
Pan Ma ${ }^{1} \cdot$ Xiaoxin Tang $^{2} \cdot$ Li Zhang $^{2} \cdot$ Xinzi Wang $^{1} \cdot$ Weimin Wang ${ }^{3} \cdot$ Xiaoling Zhang $^{1} \cdot$ Shigong Wang ${ }^{1} \cdot$ Ning Zhou $^{4}$
}

Received: 23 April 2021 / Revised: 4 October 2021 / Accepted: 7 October 2021 / Published online: 25 October 2021

(C) ISB 2021

\begin{abstract}
Under the variant climate conditions in the transitional regions between tropics and subtropics, the impacts of climate factors on influenza subtypes have rarely been evaluated. With the available influenza A (Flu-A) and influenza B (Flu-B) outbreak data in Shenzhen, China, which is an excellent example of a transitional marine climate, the associations of multiple climate variables with these outbreaks were explored in this study. Daily laboratory-confirmed influenza virus and climate data were collected from 2009 to 2015 . Potential impacts of daily mean/maximum/minimum temperatures $\left(T / T_{\max } / T_{\min }\right)$, relative humidity (RH), wind velocity $(V)$, and diurnal temperature range (DTR) were analyzed using the distributed lag nonlinear model (DLNM) and generalized additive model (GAM). Under its local climate partitions, Flu-A mainly prevailed in summer months (May to June), and a second peak appeared in early winter (December to January). Flu-B outbreaks usually occurred in transitional seasons, especially in autumn. Although low temperature caused an instant increase in both Flu-A and Flu-B risks, its effect could persist for up to 10 days for Flu-B and peak at $17 \mathrm{C}$ (relative risk (RR) $=14.16,95 \%$ CI: 7.46-26.88). For both subtypes, moderate-high temperature $(28 \mathrm{C})$ had a significant but delayed effect on influenza, especially for Flu-A $(\mathrm{RR}=26.20,95 \% \mathrm{CI}: 13.22-51.20)$. The Flu-A virus was sensitive to RH higher than 76\%, while higher Flu-B risks were observed at both low $(<65 \%)$ and high $(>83 \%)$ humidity. Flu-A was active for a short term after exposure to large DTR (e.g., DTR $=10 \mathrm{C}, \mathrm{RR}=12.45,95 \%$ CI: 6.50-23.87), whereas Flu-B mainly circulated under stable temperatures. Although the overall wind speed in Shenzhen was low, moderate wind $(2-3 \mathrm{~m} / \mathrm{s})$ was found to favor the outbreaks of both subtypes. This study revealed the thresholds of various climatic variables promoting influenza outbreaks, as well as the distinctions between the flu subtypes. These data can be helpful in predicting seasonal influenza outbreaks and minimizing the impacts, based on integrated forecast systems coupled with short-term climate models.
\end{abstract}

Keywords Influenza $\cdot$ Outbreak $\cdot$ Virus subtype $\cdot$ Climatic factor $\cdot$ Shenzhen

\section{Introduction}

Ma and Tang are contributed equally to this work.

Pan Ma

mapan@cuit.edu.cn

1 Plateau Atmosphere and Environment Key Laboratory of Sichuan Province, College of Atmospheric Science, Chengdu University of Information Technology, Chengdu 610225, Sichuan, China

2 Shenzhen National Climate Observatory, Shenzhen Meteorological Bureau, Shenzhen 518000, China

3 Shangluo Meteorological Bureau, Shangluo 726000, Shanxi, China

4 The First Hospital of Lanzhou, Lanzhou 730000, Gansu, China
Seasonal influenza causes annual epidemics, leading to approximately $3-5$ million cases and $250,000-500,000$ deaths worldwide (World Health Organization 2018). The public is concerned about new influenza pandemics. Older people and young children, as well as those with certain health conditions (asthma, cardiovascular disease, diabetes, etc.), are at high risk of serious flu complications (Nimbalkar and Tripathi 2016; Virlogeux et al. 2015). Studies have revealed that seasonal influenza is virus type specific and climate dependent (Ye et al. 2019; Alonso et al. 2007; Tamerius et al. 2013; Lofgren et al. 2007). Influenza A (Flu-A) and influenza B (Flu-B) are presently the two major viruses circulating globally, which exhibit distinctive but intriguing dynamics of infection patterns (Tang and Loh 2016). 
Generally, in temperate areas, influenza peaks once in a year during the cold season (Finkelman et al. 2007; Chong et al. 2020). But, the seasonal patterns in tropical and subtropical regions are more complicated, where influenza activity occurs year-round or with multiple epidemics in different seasons (Iha et al. 2016; Liu et al. 2018). Higher influenza activities during rainy seasons have also been found in tropical and subtropical regions (Soebiyanto et al. 2010; Moura et al. 2009). Therefore, epidemic onsets in lower latitudes are generally regarded as rather local (Du et al. 2012; Shu et al. 2010; Yu et al. 2013).

Low temperature has been detected as a major determinant for influenza, favoring both Flu-A and Flu-B under diverse climate backgrounds (Huang et al. 2017; Jaakkola et al. 2014; Soebiyanto et al. 2015; Xu et al. 2013). More specifically, in tropical and subtropical regions, there exhibits a U- or N-shaped association between Flu-A and air temperature, while Flu-B behaves differently with inconsistent patterns (Chong et al. 2020; Zhang et al. 2020). In addition, absolute/relative humidity has been associated with influenza activity across temperate and subtropical climates (Soebiyanto et al. 2014). Other climate variables, including rainfall, daily temperature range, and wind velocity, are believed to affect seasonal influenza infections as well (Gomez-Barroso et al. 2017; Shaman and Kohn 2009; Shaman et al. 2011; Tamerius et al. 2013). Further, climate factors may promote influenza infections with complex interactive effects (Wang et al. 2017). For example, Tamerius et al. (2013) indicated that "cold-dry" and "humid-rainy" conditions tended to affect influenza seasonality worldwide.

Considering the geographical heterogeneity of seasonal influenza patterns in various climatic zones, the multifaceted associations of climate conditions with influenza virus subtypes still remain unclear in the transitional regions between tropics and subtropics, such as Shenzhen, China. It is the first special economic zone in southern China, where the fast economic development has led to the highest urbanization level (100\%), with a permanent population exceeding 13.439 million (2019), and a large proportion of young residents (National Bureau of Statistics of China, http://tij. sz.gov.cn/). The summer is very hot and humid, lasting for nearly 6 months, accompanied by staged heavy rainfall due to tropical cyclones or monsoon depressions. The winter lasts for less than a month but is usually affected by cold and dry air spells.

In order to supplement the researches on seasonal influenza, we introduced the distributed lag nonlinear model (DLNM), to illuminate the detailed exposure-lag-response relations between multiple climate variables and influenza subtype outbreaks in Shenzhen, based on the laboratoryconfirmed positive specimens.

\section{Materials and methods}

\section{Data source}

The national surveillance of influenza-like illness (ILI) in China was launched in 2000, with year-round operations in sentinel hospitals in southern China (Feng et al. 2010). ILI is defined as patients suffer from acute respiratory infection and fever $\left(\geq 38^{\circ} \mathrm{C}\right)$, with cough and/or sore throat. Identified ILI cases were reported weekly through China Influenza Surveillance Information System (CISIS) by sentinel hospitals. The routine operations of CISIS, as well as the detailed procedure of sample collection and laboratory testing, have been listed in previous researches (Feng et al. 2010, 2012, 2018). Besides, the vaccination of seasonal influenza has yet to be included in the national immunization program of China (Zhang et al. 2020).

An ILI outbreak refers to the abnormal ILI increase in the same area within a short period, i.e., ten or more cases occurring within 1 week. Once an epidemic report is received, the local Center for Disease Control and Prevention (CDC) was requested to verify the situation immediately and carry out epidemiological investigations. The respiratory tract specimens (e.g., throat swab, nasal swab, nasopharyngeal swab) should be collected within 3 days of onset. All of specimens of severe or dead patients should be included, new cases ought to be collected first. For each outbreak, at least 10 specimens (if less than 10, all are taken) were collected and sent to the influenza surveillance network laboratory. The virus' subtypes or strains were then determined by nucleic acid detection within $24 \mathrm{~h}$. If the etiological diagnosis was not clear, the sampling batch and quantity could be increased appropriately. Finally, detailed information about each outbreak was entered into CISIS of the Chinese CDC (http:// www.chinaivdc.cn/cnic/zyzx/).

A total of 1157 ILI outbreak epidemics occurred in the 10 districts of Shenzhen (i.e., Baoan, Guangming, Longhua, Nanshan, Futian, Luohu, Longgang, Yantian, Pingshan, and Dapeng districts) between 1 January 2009 and 31 December 2015, with a total of 5744 specimens being tested. We collected daily laboratory-confirmed positive case data from Shenzhen CDC. The data included dates and addresses of epidemic outbreaks, the number of patients with fever and their main symptoms, details of sampling and detection, as well as the final test results. According to the dates of outbreaks, a consecutive time series (2556 days) of daily confirmed cases was built and analyzed subsequently. The analysis excluded the A/H1N1 pandemic season April 2009-April 2010, which was investigated and counted separately, to focus on seasonal influenza patterns.

Meteorological data for Shenzhen from 1 January 2009 to 31 December 2015 were obtained from the 
China Meteorological Data Network (http://data.cma.cn/). Observed parameters mainly included daily mean/maximum/minimum temperatures $\left(T / T_{\max } / T_{\min }\right)$, mean relative humidity (RH), wind velocity $(V)$, daily precipitation, and sunshine duration. Moreover, the daily temperature range (DTR) was also calculated from the daily maximum and minimum temperatures.

\section{Statistical analysis}

To assess the potential nonlinear impacts of meteorological factors on influenza outbreaks, the generalized additive model (GAM) with quasi-Poisson family of distributions (Hastie and Tibshirani 1995) and a DLNM (Gasparrini and Armstrong 2010; Gasparrini 2011) were employed. The models were constructed separately for Flu-A and Flu-B. For the ease of comparison, all parameters and settings of confounding factors were the same for both subtypes.

In order to control long-term trend and seasonality, the GAMs were adjusted for trends by including a counter variable for each day of the time series and fitting a smoothing spline $(d f=4 \times 7)$. We used 4-7 $d f$ per year for the trend in the sensitivity analysis, which revealed slightly different patterns of temperature-influenza relationship; $4 d f$ per year was finally selected. Holidays and day of the week (DOW) were marked by categorical dummy variables in the GAMs.

The bi-dimensional "cross-basis" of $T / T_{\max } / T_{\min }$ was built in DLNMs separately. A natural cubic spline with $5 d f$ was used for temperature metrics, and a polynomial function (degree $=4$ ) was used to capture the lags up to 14 days. It was based upon previously reported incubation period of influenza, the Akaike information criterion (AIC), as well as the stability of the revealed exposure-response relationships between temperature and influenza subtypes (Dai et al. 2018; Zhang et al. 2020).

To capture the potential confounding effects of RH, DTR, and $V$, cross-basis functions were also built for each of them. Referring to a previous study (Zhang et al. 2020), the maximum lag for RH was set to 14 days, with the same $d f$ as for temperature. After multiple sensitivity tests, the maximum lag of DTR and $V$ was set to 10 days to capture all effects and achieve maximum model stability, and $4 d f$ for both dimensions was selected (Zhang et al. 2020). Considering the collinearity between air temperature and solar duration or between humidity and precipitation, solar duration and precipitation were not included in our models (Table S1).

The final GAM was obtained using the following formula:

$$
\begin{aligned}
\mathrm{E}\left(\mathrm{Y}_{t}\right)= & \sum \mathrm{cb}\left(\text { climate variables, } \mathrm{df}_{1}, \mathrm{lag}, \mathrm{df}_{2}\right) \\
& +\mathrm{s}(\text { trend })+\mathrm{DOW}+\text { holiday }+\alpha
\end{aligned}
$$

where $E\left(Y_{t}\right)$ denotes estimated daily positive influenza cases on day $t ; c b()$ represents the cross-basis matrix of climate variables, and only one temperature metric could be introduced in each model; trend, holiday, and DOW are self-explanatory; $s()$ denotes the smoothing spline functions, and $\alpha$ is the model residuals.

Relative risk (RR), representing the risk of onset caused by a unit change of certain climate factor $\left(\Delta V a r_{i}\right)$ relative to its reference $(R R=1)$, was used to quantify the impact of climate conditions on influenza. RR and its $95 \%$ confidence intervals (CIs) were calculated as follows:

$\mathrm{RR}=\exp \left(\beta_{\mathrm{i}} \times \Delta \mathrm{Var}_{\mathrm{i}}\right)$

$95 \% \mathrm{CI}=\exp \left[\left(\beta_{\mathrm{i}} \pm 1.96 \mathrm{SE}\right) \times \Delta \operatorname{Var}_{\mathrm{i}}\right]$

$\beta_{i}$ represents the effects of $\operatorname{Var}_{i}$ on influenza subtype outbreaks, and $S E$ is the standard error of $\beta_{i}$. All statistical tests were two-sided, and values of $P<0.05$ were considered statistically significant. Further, auto-correlation and partial auto-correlation coefficients of the model residuals are in Fig. S1. The R 3.6.1 software (http://www.r-project. org) was used for model fitting. The "mgcv" and "dlnm" packages in $\mathrm{R}$ were employed.

\section{Results}

\section{Descriptive statistics}

A total of 3330 positive specimens were confirmed, including 1574 Flu-A specimens (47.3\%) and 1756 Flu-B specimens $(52.7 \%)$. Table 1 summarizes the daily positive cases and climate variables throughout 2009-2015. The annual range of mean temperature, relative humidity, DTR, wind speed, and solar duration in Shenzhen was $5.4-33 \mathrm{C}, 19-100 \%, 1.3-13.8 \mathrm{C}, 0.3-6.7 \mathrm{~m} / \mathrm{s}$, and $0.0-12.5 \mathrm{~h}$, respectively (Table 1 ). The percentiles of all collected meteorological variables are listed in Table S2.

Table 1 Statistical summary of confirmed influenza cases from 2009 to 2015 in Shenzhen and the corresponding meteorological variables

\begin{tabular}{lclrll}
\hline & Mean & Median & SD & Min & Max \\
\hline Flu-A & 0.616 & 0 & 2.48 & 0 & 33 \\
Flu-B & 0.687 & 0 & 2.50 & 0 & 32 \\
$\mathrm{~T}\left({ }^{\circ} \mathrm{C}\right)$ & 23.19 & 24.60 & 5.60 & 5.40 & 33.00 \\
$T_{\max }\left({ }^{\circ} \mathrm{C}\right)$ & 26.83 & 28.10 & 5.63 & 7.20 & 36.40 \\
$T_{\min }\left({ }^{\circ} \mathrm{C}\right)$ & 20.74 & 22.10 & 5.70 & 2.40 & 29.80 \\
$\mathrm{RH}(\%)$ & 73.19 & 75.43 & 12.95 & 19.00 & 100.0 \\
$\mathrm{DTR}\left({ }^{\circ} \mathrm{C}\right)$ & 6.09 & 6.10 & 1.97 & 1.30 & 13.80 \\
$\mathrm{~V}(\mathrm{~m} / \mathrm{s})$ & 2.20 & 2.10 & 0.80 & 0.30 & 6.70 \\
Solar duration $(\mathrm{h})$ & 5.29 & 5.80 & 3.79 & 0.0 & 12.50 \\
Precipitation $(\mathrm{mm})$ & 4.49 & 1.53 & 14.23 & 0.00 & 187.80 \\
\hline
\end{tabular}


In particular, the overall wind velocity in Shenzhen was low, with the $50^{\text {th }}$ and $90^{\text {th }}$ percentiles at $2.10 \mathrm{~m} / \mathrm{s}$ and $2.75 \mathrm{~m} / \mathrm{s}$, respectively (Table $\mathrm{S} 2$ ).

Table 2 The division of seasons in Shenzhen and corresponding climate conditions during 2009-2015

\begin{tabular}{lllll}
\hline & Spring & Summer & Autumn & Winter \\
\hline Date of beginning & Feb. 6 & Apr. 21 & Nov. 4 & Jan. 13 \\
Length (days) & 76 & 196 & 69 & 24 \\
Mean $T\left({ }^{\circ} \mathrm{C}\right)$ & 19.40 & 27.34 & 18.03 & 15.88 \\
Mean RH $(\%)$ & 76.36 & 75.38 & 65.81 & 66.99 \\
Mean $V(\mathrm{~m} / \mathrm{s})$ & 2.22 & 2.19 & 2.24 & 2.14 \\
Mean DTR $\left({ }^{\circ} \mathrm{C}\right)$ & 6.25 & 5.82 & 6.33 & 7.20 \\
Precipitation $(\mathrm{mm})$ & 218.9 & 1309.0 & 101.9 & 11.24 \\
Flu-A cases & 303 & 929 & 258 & 84 \\
Flu-B cases & 541 & 436 & 779 & 0 \\
\hline
\end{tabular}

\section{Division of seasons and temporal characteristics}

Considering the specific subtropical monsoon climate of Shenzhen, the seasons were divided according to Shenzhen Meteorological Bureau standards based on climatic data from 1981 to 2010 (http://weather.sz.gov.cn/). The winter ends if the 5-day moving average temperature steadily exceeds $10^{\circ} \mathrm{C}$, and the summer starts if the 5-day moving average exceeds $22^{\circ} \mathrm{C}$. The details of seasons and corresponding climate conditions from 2009 to 2015 are shown in Table 2. Particularly, no positive Flu-B case was confirmed during the winter (Table 2).

Figure 1 shows that Flu-A usually peaked during the summer months, with the highest morbidity appearing in May and June (Table S3). Flu-A may also peak in December and January in some years (Fig. 1, Table S3). Flu-B had an annual spring peak, and its autumn peak (November to December) occurred only in some years (Fig. 1).
Fig. 1 The temporal fluctuations of Flu-A, Flu-B, and climate factors in Shenzhen from 2009 to 2015 . The positive specimens during the $\mathrm{A} / \mathrm{H} 1 \mathrm{~N} 1$ pandemic season April 2009-April 2010 had been excluded

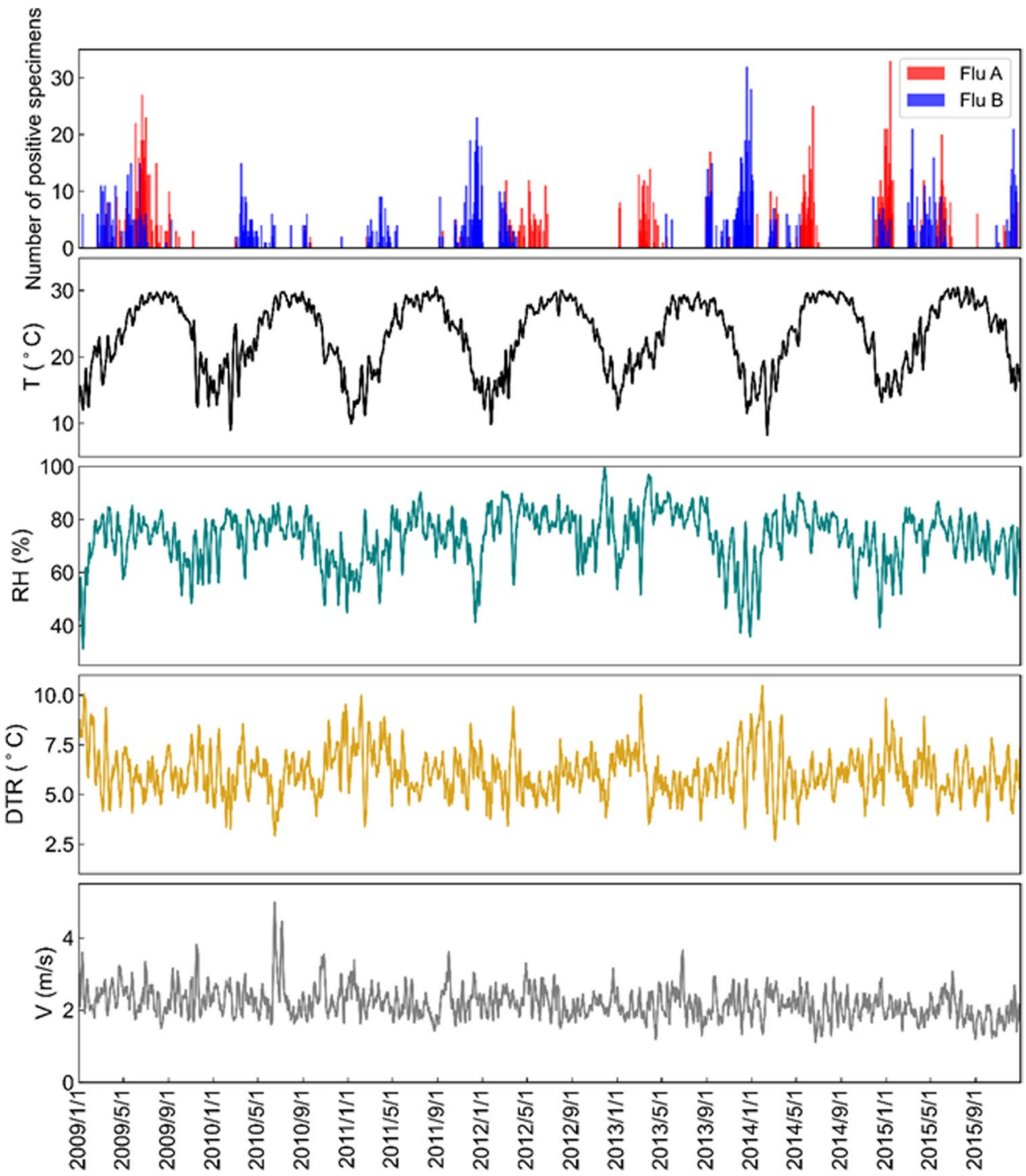


Table 3 Spearman's correlation between positive specimens of seasonal influenza outbreaks with meteorological variables

\begin{tabular}{|c|c|c|c|c|}
\hline & \multicolumn{4}{|l|}{$R$} \\
\hline & Whole year & Summer & $\begin{array}{l}\text { Spring \& } \\
\text { autumn }\end{array}$ & Winter \\
\hline \multicolumn{5}{|l|}{ Flu-A } \\
\hline$T\left({ }^{\circ} \mathrm{C}\right)$ & 0.029 & $0.06 *$ & -0.017 & -0.127 \\
\hline$T_{\max }\left({ }^{\circ} \mathrm{C}\right)$ & 0.025 & 0.039 & -0.006 & -0.081 \\
\hline$T_{\min }\left({ }^{\circ} \mathrm{C}\right)$ & 0.027 & $0.055^{*}$ & -0.023 & $-0.181^{*}$ \\
\hline RH (\%) & -0.012 & $-0.058^{*}$ & 0.031 & -0.128 \\
\hline$V(\mathrm{~m} / \mathrm{s})$ & $0.054 * *$ & $0.079 * *$ & 0.024 & -0.022 \\
\hline DTR $\left({ }^{\circ} \mathrm{C}\right)$ & -0.008 & -0.022 & 0.017 & 0.119 \\
\hline $\begin{array}{l}\text { Solar duration } \\
\text { (h) }\end{array}$ & 0.002 & 0.00 & -0.009 & 0.119 \\
\hline $\begin{array}{l}\text { Precipitation } \\
(\mathrm{mm})\end{array}$ & 0.002 & -0.019 & 0.004 & 0.022 \\
\hline \multicolumn{5}{|l|}{ Flu-B } \\
\hline$T\left({ }^{\circ} \mathrm{C}\right)$ & $-0.168 * *$ & $-0.096 * *$ & $-0.071^{*}$ & - \\
\hline$T_{\max }\left({ }^{\circ} \mathrm{C}\right)$ & $-0.157 * *$ & $-0.079 * *$ & -0.051 & - \\
\hline$T_{\min }\left({ }^{\circ} \mathrm{C}\right)$ & $-0.170 * *$ & $-0.097 * *$ & $-0.077^{*}$ & - \\
\hline RH (\%) & $-0.073 * *$ & -0.024 & $-0.109 * *$ & - \\
\hline$V(\mathrm{~m} / \mathrm{s})$ & 0.013 & 0.025 & -0.022 & - \\
\hline DTR $\left({ }^{\circ} \mathrm{C}\right)$ & $0.054 * *$ & 0.037 & 0.054 & - \\
\hline $\begin{array}{l}\text { Solar duration } \\
\text { (h) }\end{array}$ & -0.031 & -0.012 & $0.066^{*}$ & - \\
\hline $\begin{array}{l}\text { Precipitation } \\
(\mathrm{mm})\end{array}$ & $-0.055^{* *}$ & -0.024 & -0.049 & - \\
\hline
\end{tabular}

Double and single asterisks indicate $R$ is statistically significant at the 0.01 level and 0.05 level, respectively

\section{Correlation analysis}

Table 3 presents the bivariate correlations between positive specimens and climate variables. In summer, Flu-A correlated positively with $T, T_{\min }$, and $V$, while negatively with RH. These relationships were barely observed during other seasons (Table 3). In contrast, a significant negative relationship was found between Flu-B and temperature metrics, RH, and rainfall, except in winter (Table 3). Nonetheless, the relatively weak significance might be due to the sample size (2556 days) or interrelationship among variables.

\section{Associations between influenza outbreaks with climate variables}

DLNMs suggested apparent nonlinear cumulative associations between climate variables with outbreaks of Flu-A and Flu-B (Fig. 2). Table 4 lists the RRs of both subtypes associated with specific climatic variables at different lags. Similar overall effects of three temperature metrics on influenza activities were revealed (Fig. 2a, b). For mean temperature, the risk of Flu-A started increasing when the temperature dropped below $24.6{ }^{\circ} \mathrm{C}$, and it peaked at $11{ }^{\circ} \mathrm{C}$ with $\mathrm{RR}$ of
84.95 (95\% CI: 26.34-274.98). Relatively high temperature (27-30 ${ }^{\circ} \mathrm{C}$ ) also promoted the spread of Flu-A, with another peak occurring at $28^{\circ} \mathrm{C}(\mathrm{RR}=26.20,95 \% \mathrm{CI}$ : $13.22-51.20)$ (Fig. 2a). In contrast, moderately low temperature associated with higher Flu-B risk, peaking at $17 \mathrm{C}(\mathrm{RR}=14.16,95 \% \mathrm{CI}$ : 7.46-26.88) (Fig. 2b). Moderate-high temperature was also found to promote Flu-B activity (Fig. 2b). Table S4 compares RR of two subtypes associated with three temperature metrics.

Further, J- or V-shaped relationships between $\mathrm{RH}$ and risks of Flu-A and Flu-B are shown in Fig. 2a and b. RH exceeding $76 \%$ favored Flu-A infection, while more Flu-B was observed at both low $(<65 \%)$ and high $(>83 \%)$ humidity. In terms of DTR, large DTR $\left(10{ }^{\circ} \mathrm{C}\right)$ exerted more Flu-A infections ( $\mathrm{RR}=12.45,95 \% \mathrm{CI}$ : $6.50-23.87)$, whereas the highest Flu-B risk was observed at DTR $<3{ }^{\circ} \mathrm{C}$ (Fig. 2a, b). Significant associations were also revealed between moderate wind $(2-3 \mathrm{~m} / \mathrm{s})$ and both subtypes, relative to extreme conditions (reference $=4 \mathrm{~m} / \mathrm{s}$ ) (Fig. $2 \mathrm{a}, \mathrm{b}$ ).

The delayed associations of specific temperatures with influenza outbreaks are shown in Fig. 3. Moreover, the overall exposure-lag-response plots of temperature and $\mathrm{RH}$ are presented in Figs. S2 and S3. The $5^{\text {th }}\left(12.8^{\circ} \mathrm{C}\right), 75^{\text {th }}\left(28^{\circ} \mathrm{C}\right)$, and $95^{\text {th }}\left(29.9^{\circ} \mathrm{C}\right)$ percentiles of temperature indicated the cold, moderately hot, and very hot weathers, respectively. High risks for both subtypes appeared under low temperature from lag 0 day, while the persistence time was longer for Flu-B (10 days) than Flu-A (4 days) (Fig. 3, Table 4). Extremely high temperature $\left(29.9^{\circ} \mathrm{C}\right)$ had longer reaction delay for both flu subtypes compared with moderate conditions $\left(28^{\circ} \mathrm{C}\right)$, and the impact was especially prominent for Flu-A (Fig. 3, Table 4).

Figure 4 displays the effect of specific RH, with a unified reference of $75 \%$. Overall, high $\mathrm{RH}$ promoted the spread of both subtypes in lag periods, with a higher risk being revealed for Flu-B (Fig. 4, Table 4). Low RH also increased Flu-B risk with persistent effects (Fig. 4, Table 4). The extreme RH ( $>91 \%$ or $<48 \%$ ) was rarely observed (Table S2), so the accuracy of time series models might be limited.

The DTR of $4{ }^{\circ} \mathrm{C}, 6^{\circ} \mathrm{C}$, and $9{ }^{\circ} \mathrm{C}$ represented the small $\left(10^{\text {th }}\right)$, moderate $\left(50^{\text {th }}\right)$, and large $\left(90^{\text {th }}\right)$ diurnal ranges of temperature, respectively (Fig. 5). Flu-A was active on lag 1-3 days after exposure to large DTR, while the effect of small DTR occurred with more delay. Flu-B was mainly sensitive to moderate and small DTRs, with 1-day lag.

With regard to the small wind velocity as well as its cumulative effect revealed in Fig. 2, RRs of influenza associated with $V=2 \mathrm{~m} / \mathrm{s}$ are listed in Table 4.

\section{Discussion}

This study was the first to evaluate the associations between influenza subtype outbreaks and various climatic variables in Shenzhen, China, under its geographical and climatic 

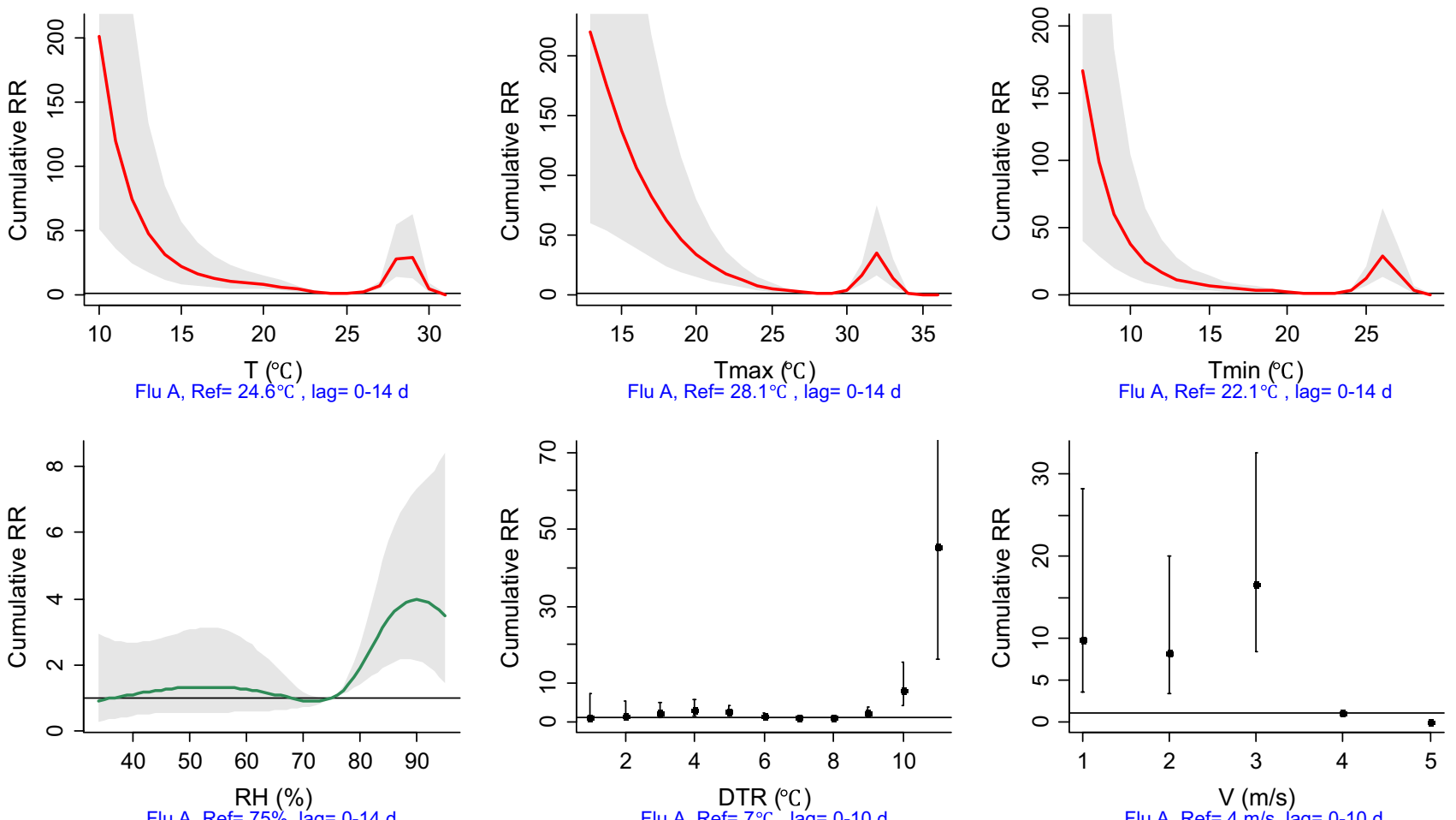

(a)
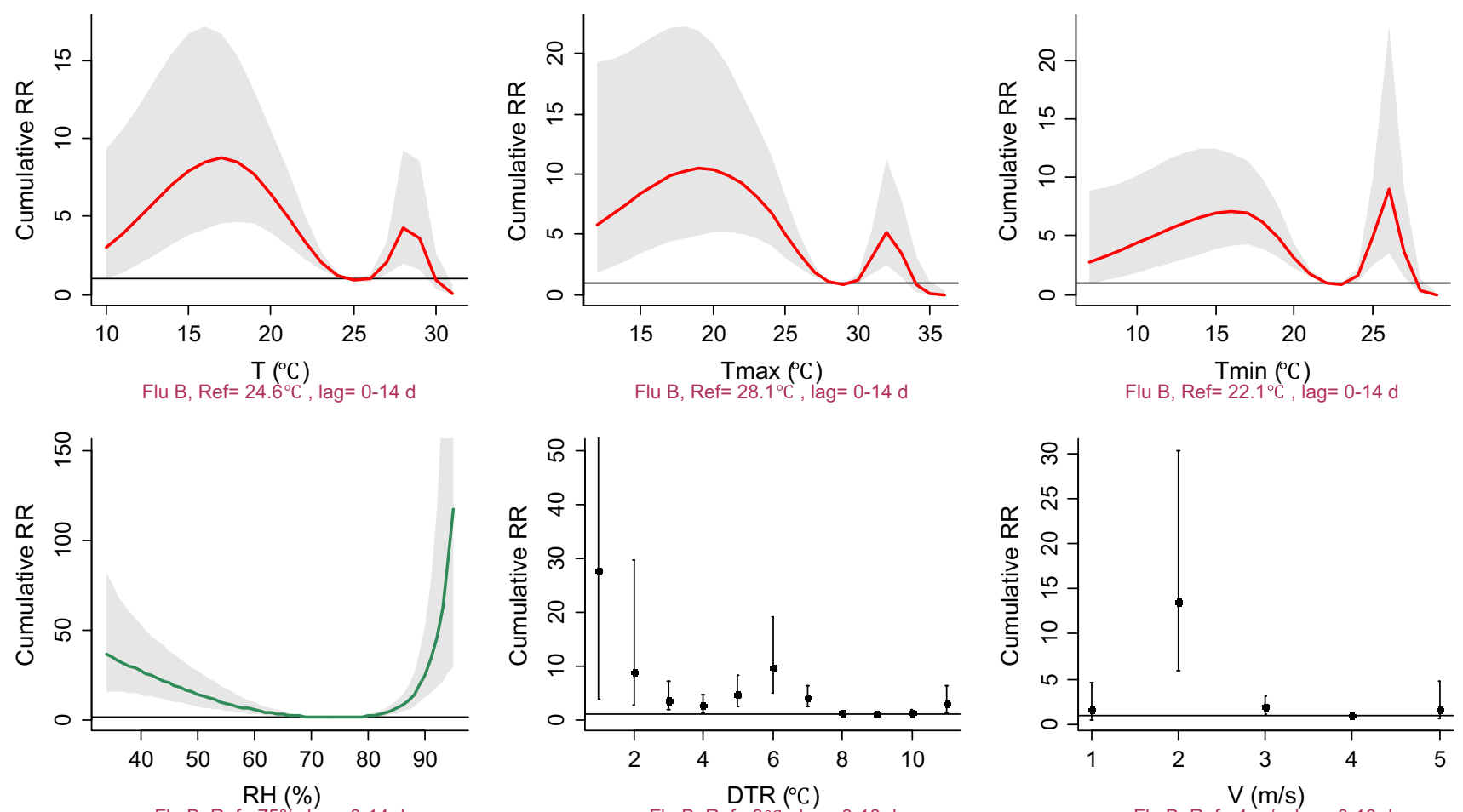

(b)

Fig. 2 Cumulative associations between climate variables with a Flu-A and b Flu-B in Shenzhen (the reference values (Ref) for temperatures and RH were their medians, and those for DTR and $V$ were their lowest RR points) 
Table 4 The RRs with 95\% CI of Flu-A and Flu-B associated with climatic variables at different lags in Shenzhen, from 2009 to 2015

Fig. 3 Lag-response association at specific mean temperatures of a Flu-A and b Flu-B. The continuous bold lines represent the estimated influenza risks, and the dotted lines are the $95 \%$ confidence intervals

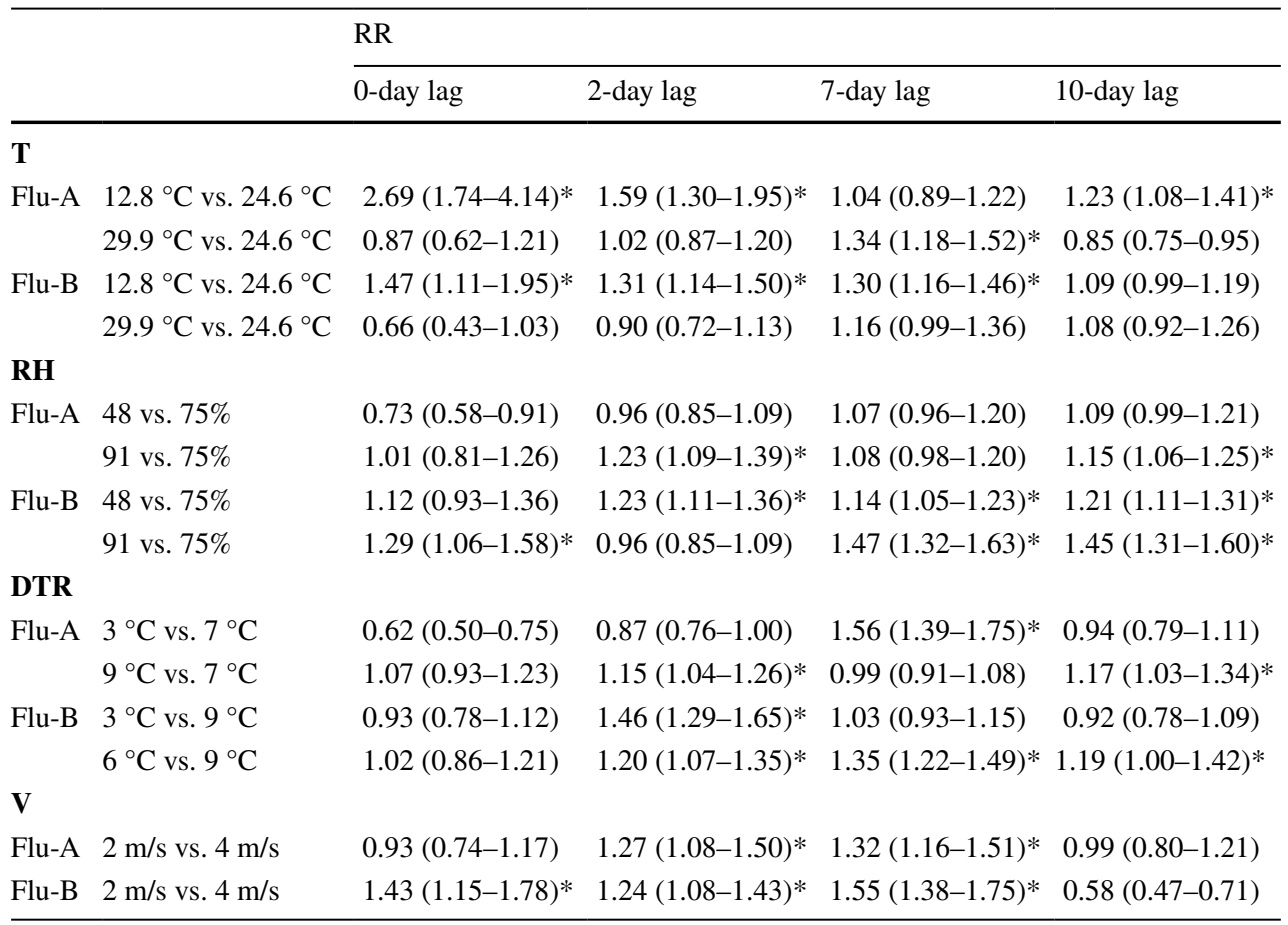

*Significant results

(a) Flu $\mathrm{A}$

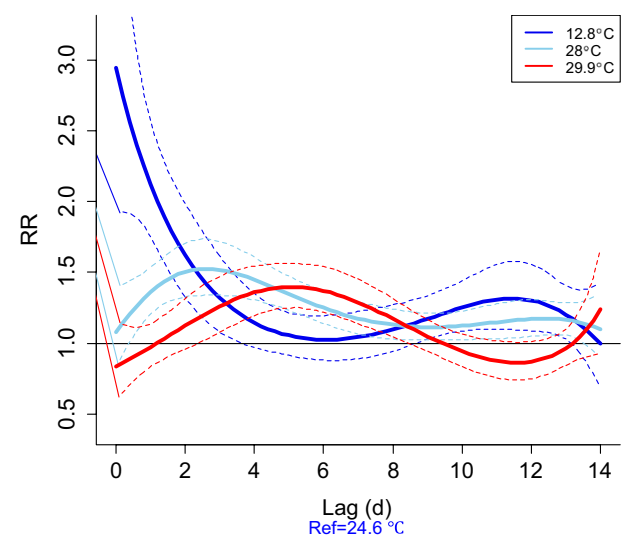

Fig. 4 Lag-response associatio between RH with Flu-A and Flu-B (ref $=75 \%$, lag $=14$ days). The continuous bold lines represent the estimated influenza risks, and the dotted lines are the $95 \%$ confidence intervals (a) Flu A

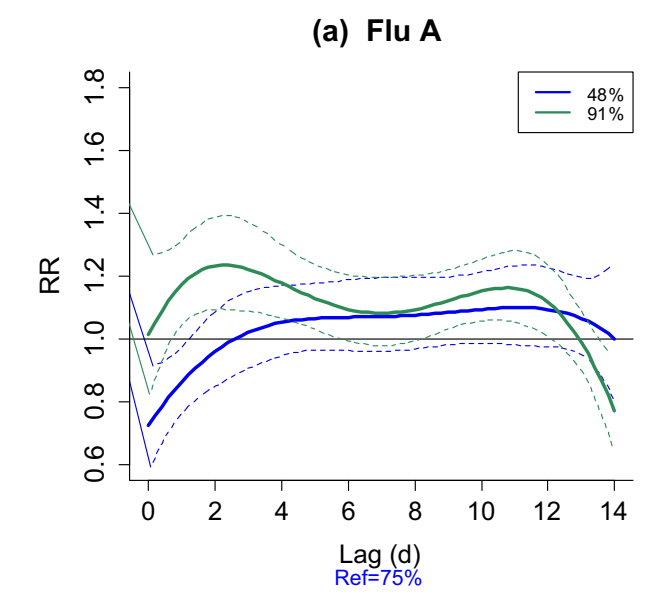

(b) Flu B

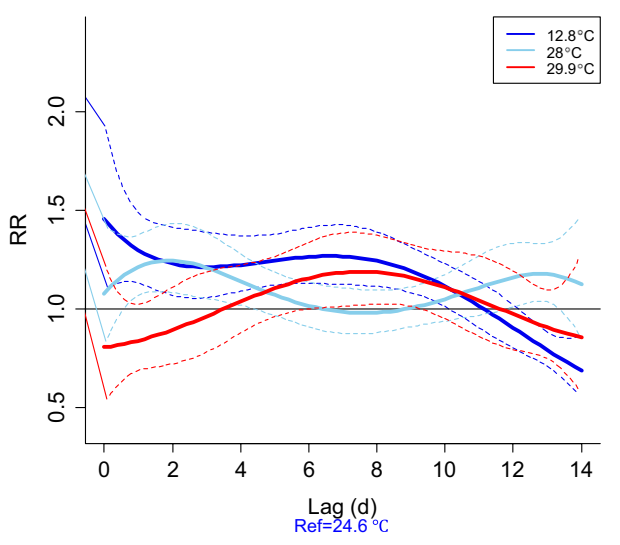

(b) Flu B

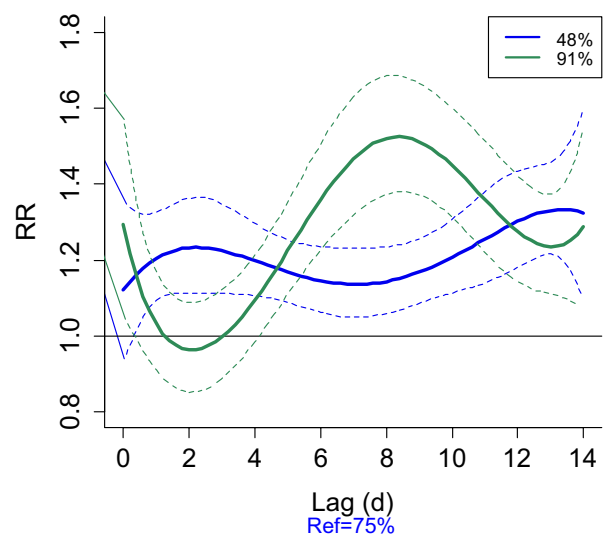


Fig. 5 Lag-response association at specific DTRs of Flu-A and Flu-B. DTR of $7{ }^{\circ} \mathrm{C}$ and $9{ }^{\circ} \mathrm{C}$ corresponds to the lowest cumulative RR for Flu-A and Flu-B, respectively. The solid dots are the estimated influenza risks, and the error bars are the 95\% confidence intervals
Flu A



Flu B

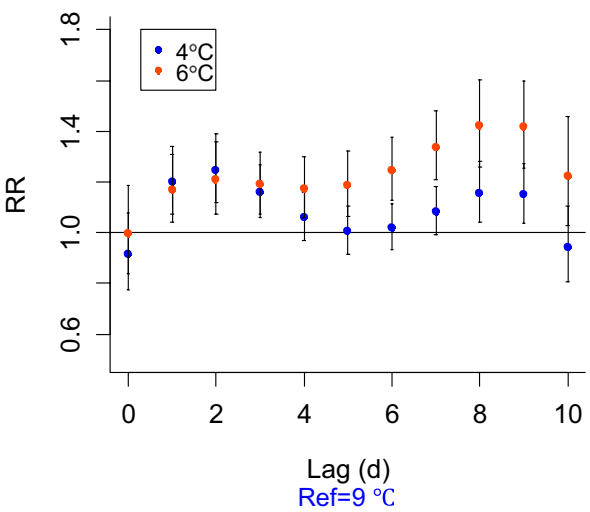

conditions. Three temperature metrics, RH, DTR, and $V$, were revealed to be associated with Flu-A and Flu-B nonlinearly by different time lags.

Flu-A had an annual peak in early summer, with a second peak occasionally occurring in winter. Flu-B was mainly detected in March and between November and December. These findings are generally consistent with previous studies, which reported the semiannual epidemic in the summer in subtropical cities like Hong Kong, Shanghai, and Singapore (Yang et al. 2018a, b; Ye et al. 2019). At midlatitudes of China, Flu-A peaks in winter and summer, while the activity of Flu-B predominates in cold seasons (Meng et al. 2016; Zhang et al. 2020). Yu et al. (2013) found that influenza circulates in southern China with a major peak occurring in January to February, and minor ones in June to August. Nevertheless, in Shenzhen, no Flu-B outbreak occurred in winter (January 13-February 5), most likely due to the short duration and specific climate characteristics.

Air temperature was significantly associated with influenza activity, with similar relations of three metrics to positive specimens. The exposure-response curves mainly indicated high cumulative risk of Flu-A during cold weather. Cold weathers were generally considered to lengthen the survival of influenza virus (Cheng et al. 2016; Liao et al. 2005; Polozov et al. 2008). High temperature also promoted Flu-A outbreaks, and similar finding was reported in Hong Kong (Chan et al. 2009). Compared with Flu-A epidemic in the subtropical city Shanghai, RR peaked at warmer weather in Shenzhen, i.e., $28{ }^{\circ} \mathrm{C}$ vs. $25.8^{\circ} \mathrm{C}$ (Zhang et al. 2020). An experimental study revealed aerosol transmission was inefficient at $30{ }^{\circ} \mathrm{C}$, and the transmission via direct contact was enhanced in tropical regions (Lowen et al. 2008). Supported by Zhang et al. (2020), extremely hot temperature did not promote the spreads of both subtypes, possible confounders including the decreased outdoor exposures, popularization of air conditioning, and decreased viral activity. Two aspects could explain the overall weak relationships between Flu-A and air temperature in seasons other than summer. On the one hand, very few positive samples were detected, adding to the uncertainty of statistical methods. On the other hand, compared to temperate zones, the annual temperature variation as well as low temperature effect was smaller in Shenzhen.

We found that Flu-B was negatively associated with temperature throughout the year, which was consistent with previous studies in subtropical China (Zhang et al. 2020; Yu et al. 2013). Flu-B was particularly active in moderate cold conditions, with the highest RR at $17^{\circ} \mathrm{C}$. Similar situations were also observed in $\mathrm{H} 5 \mathrm{~N} 1$ and $\mathrm{H} 7 \mathrm{~N} 9$, with the highest risks in $5-10^{\circ} \mathrm{C}$ and $10-15^{\circ} \mathrm{C}$, respectively (Li et al. 2015). Besides, this threshold $\left(17^{\circ} \mathrm{C}\right)$ was obviously higher than that $\left(5^{\circ} \mathrm{C}\right)$ in Jiangsu Province, China (Dai et al. 2018). In short, for subtropical climate zones, moderate cold weathers seemed to have stronger effects on Flu-B virus activity than extremely low temperatures. Concerning residents living in low altitudes, relatively low temperatures may also increase their susceptibility and weaken the immunities (Lofgren et al. 2007).

Under the climate background of Shenzhen, Flu-A was mainly promoted by $\mathrm{RH}$ exceeding its median (75\%), which was highly consistent with a recent study (Chong et al. 2020). In contrast, more Flu-B outbreaks were observed at both dry and humid conditions. Low RH has been found to dominate the airborne transmission (Sundell et al. 2016; Yang and Marr 2011). However, this effect might be weakened in humid zones. For temperate and some subtropical zones, relatively high and low humidity has been revealed to favor the spread of influenza, regardless of Flu-A or Flu-B (Lowen et al. 2007; Hemmes et al. 1960). In tropical areas, peaks of infection were also related to rainy seasons/high humidity, as reported in Western India, northern Brazil, Hong Kong, and Arizona (Soebiyanto et al. 2010; Chew et al. 1998; Moura et al. 2009). Cold and humid conditions might also greatly enhance the indoor transmissions (Chong et al. 2020). Nevertheless, wet environment was recognized to block viral replication (Tamerius et al. 2013; Lowen et al. 
2007). The air conditioning usually lowers humidity, and whether it affects host behavior, physiology, or virus survival remains unclear (Chong et al. 2020). Therefore, mechanisms between RH and influenza activity need to be further explored.

Large DTR associated with greater Flu-A risk, while small DTR promoted Flu-B activity. In the dry seasons of Hong Kong, DTR also positively associated with confirmed influenza cases, but not modified by influenza types ( $\mathrm{Li}$ et al. 2018). Besides, more of older patients were observed to contract influenza in Beijing under large temperature variations (Lao et al. 2018). The physiological mechanisms of DTR on influenza were not elucidated up to now. Several possible reasons are listed as follows. Firstly, a large temperature range may increase respiratory vulnerability and induce the onset of a respiratory event (Imai et al. 1998). Secondly, large diurnal temperature variations could influence humoral and cellular immunity (Bull 1980). Thirdly, large DTR usually occurs in transition seasons, during which frequent fluctuations in temperature, humidity, and wind may also add influenza risk.

In addition, moderate wind speed was found to increase influenza risk in Shenzhen, which was inconsistent with previous results (Yuan et al. 2006; Firestone et al. 2012). It has been indicated that high wind may lead to increased infections of influenza, respiratory syncytial virus, and severe acute respiratory syndrome virus (du Prel et al. 2009; Firestone et al. 2012). Although large wind velocity promoted the longer travel of airborne aerosols (Sematimba et al. 2012), relatively still air might favor the stay and spread of influenza virus in the same area, thus leading to more outbreaks of influenza in schools, childcare centers, or other crowded spaces.

There are several strengths in the study. First, it is a systematic and comprehensive analysis of the lag-nonlinear relationships between multiple climate factors and influenza outbreaks in Shenzhen, which has an atypical subtropical climate and a unique social-economic status in China. This is crucial for optimizing public health decisions on vaccination strategy and healthcare resource arrangement. Second, the influenza outbreak data from Shenzhen CDC was continuous in time and in a standard format. The data had high surveillance coverage in all the ten districts of Shenzhen. Third, two influenza virus subtypes were compared in their epidemic characteristics as well as relations to climatic conditions. Finally, our findings may also be relevant to the complex transmission patterns of influenza in other countries, especially for transitional regions between the subtropics and tropics.

A few limitations also should be noted. First, the representativeness of results might be modified by age and gender, and Shenzhen has its uniqueness in age structure. Thus, detailed investigations on subgroups are needed in future. Second, the data accuracy might be affected by sample collection and processing approaches. Although reported cases of most outbreak epidemics were less than 10 , slight deviation may still exist in representativeness of positive specimens due to the sampling regulation. Third, air pollutants, indoor temperature and humidity conditions, host susceptibility, as well as viral migration could also affect the transmission of influenza (Lofgren et al. 2007). The air quality monitoring was started in 2013 in Shenzhen, so the pollution data was not included in our models. Finally, the potential synergetic effects among multiple variables, e.g., $T$ and DTR, and $T$ and RH, need further exploration through diversified approaches.

\section{Conclusion}

Our study suggested that climate conditions had significant and multidimensional effects on influenza outbreaks in Shenzhen, China. The risky meteorological thresholds for influenza A and B were distinct with those in typical subtropical or tropical areas. The results extended our understanding of the driving effects of climate on influenza infection and might help develop an alert system to improve the response capacity to influenza epidemics, based on shortterm climate predictions. Even so, the climate variables should always be used carefully due to the complexity of revealed associations.

Supplementary Information The online version contains supplementary material available at https://doi.org/10.1007/s00484-021-02204-y.

Funding This research was supported by the "Key Project of Ensuring Urban Safety and People's Livelihood" (20200605), Shenzhen National Climate Observatory, China; the open fund of Shangluo Key Laboratory of Climate Adaptive City (SLSYS2019004), Shangluo Meteorological Bureau, China; the National key Research and Development Program of China (2016YFA0602004), Ministry of Science and Technology of the People's Republic of China, China; and the Chengdu University of Information Technology scientific research fund (KYTZ201811), Chengdu University of Information Technology, China.

\section{Declarations}

Conflict of interest The authors declare no competing interests.

\section{References}

Alonso WJ, Viboud C, Simonsen L, Hirano EW, Daufenbach LZ, Miller MA (2007) Seasonality of influenza in Brazil: a traveling wave from the Amazon to the subtropics. Am J Epidemiol 165:1434-1442 
Bull G (1980) The weather and deaths from pneumonia. Lancet 315:1405-1408

Chan PK, Mok HY, Lee TC, Chu IM, Lam WY, Sung JJ (2009) Seasonal influenza activity in Hong Kong and its association with meteorological variations. J Med Virol 81(10):1797-1806

Cheng YH, Wang CH, You SH, Hsieh NH, Chen WY, Chio CP et al (2016) Assessing coughing-induced influenza droplet transmission and implications for infection risk control. Epidemiol Infect 144:333-345

Chew FT, Doraisingham S, Ling AE, Kumarasinghe G, Lee BW (1998) Seasonal trends of viral respiratory tract infections in the tropics. Epidemiol Infect 121(1):121-128

Chong KC, Lee TC, Bialasiewicz S, Chen J, Smith DW, Choy WSC et al (2020) Association between meteorological variations and activities of influenza A and B across different climate zones: a multi-region modelling analysis across the globe. J Infect 80(1):84-98

Dai QG, Ma W, Huang HD, Xu K, Qi X, Yu HY et al (2018) The effect of ambient temperature on the activity of influenza and influenza like illness in Jiangsu Province, China. Sci Total Environ 645:684-691

du Prel JB, Puppe W, Gröndahl B, Knuf M, Weigl JA, Schaaff F, Schmitt HJ (2009) Are meteorological parameters associated with acute respiratory tract infections? Clin Infect Dis 49(6):861-868

Du X, Dong L, Lan Y, Peng Y, Wu A, Zhang Y et al (2012) Mapping of H3N2 influenza antigenic evolution in China reveals a strategy for vaccine strain recommendation. Nat Commun 3:709

Feng LZ, Mounts AW, Feng YX, Luo Y, Yang P, Feng ZJ et al (2010) Seasonal influenza vaccine supply and target vaccinated population in China, 2004-2009. Vaccine 28:6778-6782

Feng LZ, Peng ZB, Wang DY, Yang P, Yang J, Zhang YY et al (2018) Technical guidelines for seasonal influenza vaccination in China, 2018-2019. Chinese Journal of Epidemiology 39(11):1413-1425

Feng LZ, Shay DK, Jiang Y, Zhou H, Chen X, Zheng YD et al (2012) Influenza-associated mortality in temperate and subtropical Chinese cities, 2003-2008. Bull World Health Organ 90(4):279-288B

Finkelman BS, Viboud C, Koelle K, Ferrari MJ, Bharti N, Grenfell BT (2007) Global patterns in seasonal activity of influenza A/ H3N2, A/H1N1, and B from 1997 to 2005: viral coexistence and latitudinal gradients. PLoS One 2: e1296.

Firestone SM, Cogger N, Ward MP, Toribio JAL, Moloney BJ, Dhand NK (2012) The Influence of meteorology on the spread of influenza: survival analysis of an equine influenza (A/H3N8) Outbreak. PLoS One 7: e35284.

Gasparrini A (2011) Distributed lag linear and non-linear models in R: the package dlnm. J Stat Softw 43:1-20

Gasparrini A, Armstrong B (2010) Time series analysis on the health effects of temperature: advancements and limitations. Environ Res 110(6):633-638

Gomez-Barroso D, León-Gómez I, Delgado-Sanz C, Larrauri A (2017) Climatic factors and influenza transmission, Spain, 2010-2015. Int J Environ Res Public Health 14:1469

Hastie T, Tibshirani R (1995) Generalized additive models for medical research. Stat Methods Med Res 4(3):187-196

Hemmes J, Winkler K, Kool S (1960) Virus survival as a seasonal factor in influenza and poliomyelitis. Nature 188:430

Huang X, Mengersen K, Milinovich G, Hu W (2017) Effect of weather variability on seasonal influenza among different age groups in Queensland, Australia: a Bayesian spatiotemporal analysis. J Infect Dis 215:1695-1701

Iha Y, Kinjo T, Parrott G, Higa F, Mori H, Fujita J (2016) Comparative epidemiology of influenza A and B viral infection in a subtropical region: a 7-year surveillance in Okinawa. Japan BMC Infect Dis 16:650

Imai Y, Nobuoka S, Nagashima J, Awaya T, Aono J, Miyake F et al (1998) Acute myocardial infarction induced by alternating exposure to heat in a sauna and rapid cooling in cold water. Cardiology 90:299-301

Jaakkola K, Saukkoriipi A, Jokelainen J, Juvonen R, Kauppila J, Vainio O et al (2014) Decline in temperature and humidity increases the occurrence of influenza in cold climate. Environ Health 13:22

Lao J, Liu Z, Liu Y, Zhang J, Jiang B (2018) Influence of diurnal temperature range on influenza incidence in the elderly. Chinese J Epidemiol 39:1454-1458

Li J, Rao Y, Sun Q, Wu X, Jin J, Bi Y et al (2015) Identification of climate factors related to human infection with avian influenza a H7N9 and H5N1 viruses in China. Sci Rep 5:18094

Li Y, Wang XL, Zheng X (2018) Impact of weather factors on influenza hospitalization across different age groups in subtropical Hong Kong. Int J Biometeorol 62:1615-1624

Liao CM, Chang CF, Liang HM (2005) A probabilistic transmission dynamic model to assess indoor airborne infection risks. Risk Anal 25:1097-1107

Liu T, Kang M, Zhang B, Xiao JP, Lin HP, Zhao YQ et al (2018) Independent and interactive effects of ambient temperature and absolute humidity on the risks of avian influenza A(H7N9) infection in China. Sci Total Environ 619-620:1358-1365

Lofgren E, Fefferman NH, Naumov YN, Gorski J, Naumova EN (2007) Influenza seasonality: underlying causes and modeling theories. $\mathbf{J}$ Virol 81(11):5429-5436

Lowen AC, Mubareka S, Steel J, Palese P (2007) Influenza virus transmission is dependent on relative humidity and temperature. PLoS Pathog 3:1470-1476

Lowen AC, Steel J, Mubareka S, Palese P (2008) High temperature $\left(30^{\circ} \mathrm{C}\right)$ blocks aerosol but not contact transmission of influenza virus. J Virol 82(11):5650-5652

Meng H, Liao Q, Suen LK, O’Donoghue M, Wong CM, Yang L (2016) Healthcare seeking behavior of patients with influenza like illness: comparison of the summer and winter influenza epidemics. BMC Infect Dis 16:499

Moura FE, Perdigão AC, Siqueira MM (2009) Seasonality of influenza in the tropics: a distinct pattern in Northeastern Brazil. Am J Trop Med Hyg 81(1):180-183

Nimbalkar PM, Tripathi NK (2016) Space-time epidemiology and effect of meteorological parameters on influenza-like illness in Phitsanulok, a northern province in Thailand. Geospat Health 11:447

Polozov IV, Bezrukov L, Gawrisch K, Zimmerberg J (2008) Progressive ordering with decreasing temperature of the phospholipids of influenza virus. Nat Chem Biol 4:248-255

Sematimba A, Hagenaars TJ, De Jong MC (2012) Modelling the windborne spread of highly pathogenic avian influenza virus between farms. PLoS One 7: e31114.

Shaman J, Goldstein E, Lipsitch M (2011) Absolute humidity and pandemic versus epidemic influenza. Am J Epidemiol 173:127-135

Shaman J, Kohn MA (2009) Absolute humidity modulates influenza survival, transmission, and seasonality. PNAS 106:3243-3248

Shu YL, Fang LQ, de Vlas SJ, Gao Y, Richardus JH, Cao WC (2010) Dual seasonal patterns for influenza. China Emerg Infect Diseases $16: 725$

Soebiyanto RP, Adimi F, Kiang RK (2010) Modeling and predicting seasonal influenza transmission in warm regions using climatological parameters. PLoS One 5(3): e9450.

Soebiyanto RP, Clara W, Jara J, Castillo L, Sorto OR, Marinero S (2014) The role of temperature and humidity on seasonal influenza in tropical areas: Guatemala, El Salvador and Panama, 20082013. PLoS One 9(6): e100659.

Soebiyanto RP, Gross D, Jorgensen P, Buda S, Bromberg M, Kaufman $\mathrm{Z}$ et al. (2015) Associations between meteorological parameters and influenza activity in Berlin (Germany), Ljubljana (Slovenia), Castile and León (Spain) and Israeli districts. PLoS One 10(8): e0134701. 
Sundell N, Andersson LM, Brittain-Long R, Lindh M, Westin J (2016) A four-year seasonal survey of the relationship between outdoor climate and epidemiology of viral respiratory tract infections in a temperate climate. J Clin Virol 84:59-63

Tamerius JD, Shaman J, Alonso WJ, Bloom-Feshbach K, Uejio CK, Comrie A et al. (2013) Environmental predictors of seasonal influenza epidemics across temperate and tropical climates. PLoS Pathog 9: e1003194.

Tang JWT, Loh TP (2016) Influenza seasonality. Curr Treat Options Infect Dis 8:343-367

Virlogeux V, Li M, Tsang TK, Feng L, Fang VJ, Jiang H (2015) Estimating the distribution of the incubation periods of human avian influenza A (H7N9) virus infections. Am J Epidemiol 182:723-729

Wang X, Jiang H, Wu P, Uyeki TM, Feng L, Lai S et al (2017) Epidemiology of avian influenza A H7N9 virus in human beings across five epidemics in Mainland China, 2013-17: an epidemiological study of laboratory-confirmed case series. Lancet Infect Dis $17: 822-832$

World Health Organization (2018) Up to 650000 people die of respiratory diseases linked to seasonal flu each year

Xu Z, Hu W, Williams G, Clements AC, Kan H, Tong S (2013) Air pollution, temperature and pediatric influenza in Brisbane, Australia. Environ Int 59:384-388
Yang J, Lau YC, Wu P, Feng L, Wang X, Chen T et al (2018a) Variation in influenza B virus epidemiology by lineage, China. Emerg Infect Dis 24:1536-1540

Yang W, Marr LC (2011) Dynamics of airborne influenza A viruses indoors and dependence on humidity. PLoS One 6: e21481

Yang X, Liu D, Wei K, Liu X, Meng L, Yu D et al (2018b) Comparing the similarity and difference of three influenza surveillance systems in China. Sci Rep 8:2840

Ye CC, Zhu WP, Yu JX, Li ZJ, Zhang YZ, Wang YP et al (2019) Understanding the complex seasonality of seasonal influenza A and B virus transmission: evidence from six years of surveillance data in Shanghai, China. Int J Infect Dis 81:57-65

Yu H, Alonso WJ, Feng L, Tan Y, Shu Y, Yang W, Viboud C (2013) Characterization of regional influenza seasonality patterns in China and implications for vaccination strategies: spatio-temporal modeling of surveillance data. PLoS Med 10: e1001552

Yuan J, Yun H, Lan W, Wang W, Sullivan SG, Jia S et al (2006) A climatologic investigation of the SARS-CoV outbreak in Beijing, China. Am J Infect Control 34:234-236

Zhang YZ, Ye CC, Yu JX, Zhu WP, Wang YP, Li ZJ et al. (2020) The complex associations of climate variability with seasonal influenza A and B virus transmission in subtropical Shanghai, China. Science of the Total Environment 701:134607 